\title{
Measuring hospital performances of regional referral hospitals in Tanzania
}

\author{
Hisahiro Ishijima*1, Shuichi Suzuki ${ }^{1}$, Fares Masaule², Violeth Mlay², Raynold John³ \\ ${ }^{1}$ Fujita Planning Co., Ltd. Tokyo, Japan \\ ${ }^{2}$ Regional Referral Hospital Management Project, Dar es Salaam, United Republic of Tanzania \\ ${ }^{3}$ Ministry of Health, Community Development, Gender, Elderly and Children, Dodoma, United Republic of Tanzania
}

Received: February 9, 2021

DOI: $10.5430 /$ jha.v10n2p1
Accepted: March 21, 2021

Online Published: March 29, 2021

\begin{abstract}
In Tanzania, regional referral hospitals (RRHs) play a major role in providing curative and diagnostic services and influence the performance of the entire health system. The results of a baseline survey conducted in 2015 to determine the status of RRHs in Tanzania indicated that there were many supportive supervisory and assessment tools for RRHs but none of them specifically focused on the performance of hospitals. In an endeavor to enhance the performance of RRHs, the Ministry of Health, Community Development, Gender, Elderly and Children (MoHCDGEC) and the President Office - Regional Administration and Local Government (PO-RALG) developed an external hospital performance assessment (EHPA) tool to analyze all aspects of the performance of RRHs. EHPA was started in 2017 to assess the performance of 28 RRHs in the country. This study examines the changes to the performance of the RRHs based on the introduction of the EHPA and the supportive interventions by the Ministry of Health. It is also studying the factors that influence the assessment of EHPA. As the results of this study, there is a great indication of the overall performance of RRHs being improved as observed from an upward gradient of average EHPA scores from 2017 to 2019 in all RRHs. This improvement is exemplified by the decrease in the standard deviation gap amongst RRHs. The three years (2017-2019) of consecutive assessment has also observed implicit competition in improving hospital services among Regional Referral Hospital Management Teams (RRHMTs) using the findings from the EHPA.
\end{abstract}

Key Words: Tanzania, Regional referral hospitals, External hospital performance assessment, Hospital management

\section{INTRODUCTION}

World Health Organization (WHO) defined Universal Health Coverage (UHC) as "all people have access to the health services they need, when and where they need them, without financial hardship", and achieving UHC became one of the top priorities of the reform agenda across many countries. ${ }^{[1,2]}$ Additionally, WHO reported in Universal Health Coverage and patient safety and quality that "patient safety and quality is an integral aspect of a successful UHC system. However, there is a noticeable lack of information on the convergence of UHC-patient safety and quality, especially in low- and middle-income countries". ${ }^{[3]}$ To achieve high-quality and safe healthcare services, proper administrative, technical, and financial inputs are needed. However, hospitals consume a considerable percentage of the total health expenditures of the country. According to the Organization for Economic Cooperation and Development (OECD), average hospital expenditures add up to $26 \%-53 \%$ of the current total health expenditures. ${ }^{[4]}$ In sub-Saharan countries, the percentages of

\footnotetext{
*Correspondence: Hisahiro Ishijima; Email: hisahiro.ishijima@gmail.com; Address: 4-17-16 Ichigaya KT Building I 5F, Kudan-minami, Chiyoda district, Tokyo, Japan. 
total hospital expenditures were estimated for some countries, such as $20.5 \%$ in Kenya ${ }^{[5]}$ and $60 \%$ in Uganda. ${ }^{[6]}$ Since the operations of government hospitals consume a large amount of the health budget; therefore, hospital functions, quality of health services and performance management need to be well assessed for effective and efficient hospital operations.

\subsection{Hospital system in Tanzania}

Tanzania is a country seeking to enhance access to healthcare services essential to achieving UHC. ${ }^{[2]}$ To strengthen access to essential quality health services, it is important to enhance healthcare facilities, especially hospital services. ${ }^{[7]}$ To expand access to essential quality medical services, the Ministry of Health Social Welfare (currently, Ministry of Health, Community Development, Gender, Elderly and Children: MoHCDGEC) strategized to improve hospital services by improving hospital management, quality of care, and patient safety. ${ }^{[7]}$ In Tanzania, the situation is similar in other sub-Saharan African countries. Public hospital expenditures are $28.5 \%-70 \%$ of total hospital expenditures in the public sector. ${ }^{[8]}$

Public hospitals in Tanzania are divided into five categories: a) national hospitals, b) specialized hospitals, c) zonal referral hospitals, d) regional referral hospitals (RRHs), and e) district hospitals. The hospitals in this study are the 28 RRHs located in 26 regions of the country. RRHs have important roles in the Tanzanian health system because they are in the capital city of each region. They act as referral centers from primary-level health facilities and they profoundly influence the performance of the entire health system. Thus, the strengthening of hospital management in RRHs is a key approach to establishing a functional health system in the country. However, RRHs have been facing several management challenges, including a chronic shortage of resources, such as budget, human resources for health, medical equipment, and supplies. These shortfalls make providing adequate healthcare services difficult. For RRHs to operate effectively and efficiently, maximum utilization of available resources is an essential strategy. This can be achieved by regional referral hospital management teams (RRHMTs) being trained in basic management skills. Improving the management of RRHs is addressed in the Health Sector Strategic Plan IV (HSSP IV) through education in governance, leadership, planning, financial management, and resource management. Therefore, the Ministry of Health, Community Development, Gender, Elderly and Children (MoHCDGEC) and the President Office Regional Administration and Local Government (PO-RALG) are striving to enhance hospital governance and management in RRHs.

\subsection{Assessment of hospital performance}

The performance of hospitals influences the performance of the overall health system. Therefore, performance assessments are required to assess the efficiency and effectiveness of healthcare services provided by hospitals. ${ }^{[9]}$ Governments throughout Europe and beyond have initiated hospital performance assessments by supporting professionals in quality management, improving accountability of hospital boards, and informing the public. In 2007, WHO Europe published Performance Assessment Tool for Quality Improvement in Hospitals: PATH. ${ }^{[9]}$ PATH has been applied to assess the performance of public hospitals in some countries. ${ }^{[10,11]}$ Additionally, there are cases of hospitals creating their own hospital performance assessment tool. ${ }^{[12-14]}$

\subsection{Monitoring and assessment of RRHs performance in Tanzania}

With its ability to provide technical advice on the spot, supportive supervision is known as an effective approach for monitoring healthcare services provided at hospitals and improving performance. The national supportive supervision guideline was developed and is widely used to monitor services at zonal, regional, and district levels.

During the hospital reform program in Tanzania between 1999 and 2009, the management of RRHs was transferred from Ministry of Health to PO-RALG. Monitoring and evaluating the performance of RRHs was a duty of PO-RALG and regional health management teams (RHMTs) had their responsibility to conduct monitoring and evaluation (M\&E) activities. However, monitoring and assessment tools specifically for RRHs did not exist before and it was difficult for the two ministries (MoHCDGEC/ PO-RALG) and RHMTs to assess the performance of RRHs. In this regard, a central management supportive supervision (CMSS) tool was developed and endorsed by the two ministries to oversee the function of RHMTs toward RRHMTs. Thereafter, the guideline for regional management supportive supervision for regional referral hospitals (RMSS-H) was developed to monitor the administrative performance of RRHs.

Due to the need for a comprehensive assessment of RRHs performance and to strengthen the internal management of their administration, the MoHCDGEC with support from the "Technical cooperation project for strengthening hospital management for regional referral hospitals in Tanzania" (Regional Referral Hospital Management Project: RRHMP) decided to develop and introduce the external hospital performance assessment (EHPA) tool and internal supportive supervision (ISS) tool specifically for RRHs. ${ }^{[15]}$

ISSN 1927-6990 E-ISSN 1927-7008 


\subsection{External hospital performance assessments for re-} gional referral hospitals

In the Guideline for ISS and EHPA, EHPA is defined as "a system for measuring the readiness of service provision of the hospital through the gap between ideal situation and status based on the standard operation procedures". ${ }^{[15]}$ The EHPA was developed to assess the performance of RRHs and encourage RRHMTs to act on improvement by using the findings of their RRH EHPA results. The main users of the EHPA tool are the assessment teams formulated by the MoHCDGEC, and the assessment is conducted at least once a year.

During the process of developing the EHPA tool, existing hospital performance assessment tools for district health facilities, regional management supportive supervision checklists, and several quality improvement checklists were studied. The EHPA is capable of assessing both service delivery and management areas, which made the tool comprehensive for assessing RRHs performance. Moreover, the following points were also considered during the development of the EHPA tool:

- Measurable for achieving objectives in the HSSP IV.

- Applicable in the current healthcare system in Tanzania.

- Sustainable for periodic assessment and reporting.

- Affordable under budget constraints.

Table 1. Areas, sub-areas, and number of indicators of EHPA

\begin{tabular}{|c|c|c|}
\hline Area & Sub-Area & No. of Indicator \\
\hline Legality & & 2 \\
\hline \multirow{3}{*}{ Hospital Management } & Hospital Management & 22 \\
\hline & Planning, Budgeting, Monitoring and Reporting & 19 \\
\hline & Working Conditions & 2 \\
\hline \multirow{3}{*}{$\begin{array}{l}\text { Use of Hospital Data for Planning and } \\
\text { Service Improvement }\end{array}$} & Function of HMIS & 5 \\
\hline & Information Use and Dissemination & 1 \\
\hline & Medical records & 3 \\
\hline Staff Performance Assessment & Staff Performance Appraisal System & 5 \\
\hline \multirow{3}{*}{ Organization of Service } & Service Provider Charter & 10 \\
\hline & Client Flow & 3 \\
\hline & Health Promotion Services & 2 \\
\hline \multirow{2}{*}{ Handling Emergencies and Referral } & Appropriate Handling Emergency Cases & 9 \\
\hline & Referral Mechanism & 2 \\
\hline \multirow{2}{*}{ Client Focus } & Client Service Charter & 2 \\
\hline & Client Satisfaction & 1 \\
\hline \multirow{2}{*}{ Social Accountability } & Social Accountability Assessment & 1 \\
\hline & Functional Hospital Advisory Boards & 3 \\
\hline \multirow{4}{*}{ Hospital Infrastructure } & Planned Preventive Maintenance (PPM) & 2 \\
\hline & Buildings & 10 \\
\hline & Utilities & 2 \\
\hline & Equipment and Furniture & 2 \\
\hline \multirow{2}{*}{$\begin{array}{l}\text { IPC, Safety Measures and Risk } \\
\text { Management }\end{array}$} & Healthcare Waste Disposal & 10 \\
\hline & Infection Prevention Control (IPC) & 13 \\
\hline Clinical Service & Outpatient and Inpatient Services & 13 \\
\hline \multirow{6}{*}{ Clinical Support Service } & Pharmaceutical Services & 13 \\
\hline & Radiology and Imaging & 4 \\
\hline & Operation Theatre & 4 \\
\hline & Laboratory Services & 7 \\
\hline & Mortuary & 3 \\
\hline & Food Service & 4 \\
\hline
\end{tabular}




\subsection{Composition of the EHPA tool}

The EHPA tool is comprised of the main checklist with 179 indicators and 14 attachment forms that supplement the checklist. It also includes an Excel form for summarizing results collected by the checklist, a presentation form for feedback sessions with RRHs, and a report for each RRH. As shown in Tables 1 and 2, the EHPA checklist consists of 12 areas and 33 sub-areas. Each sub-area has multiple indicators. Some indicators have sub-questions, and multiple questions will confirm the status of the indicator. There are eight fields that assessors had to work with: 1) Serial numbers for the area, indicators and sub-indicators; 2) Indicators; 3) Question/verification method; 4) Responses; 5) Means of verification; 6) Department/unit to be observed; 7) Score; 8) Comments.

Apart from those fields, the EHPA tool is equipped with a calculator to assist the assessors in aggregating and analyzing the results. To make the aggregation of data easier, an Excel-based aggregating form was developed. By entering the scores into the aggregating form, the average score and percentage for each area and each sub-area were calculated. Area 1 "Legality" is an item to confirm registration as a healthcare facility; however, RRHs are not subject to assessment because not all public facilities require registration.

The EHPA tool was developed in 2016 and piloted in two RRHs in 2017. Some faults were detected in the tool through the pilot test. Thus, the tool was reviewed based on technical inputs from the EHPA assessors and hospital managers where the tool was piloted.

\subsection{Rationale for the study}

This study is part of a larger study that assesses the effectiveness of project intervention for strengthening the hospital management of RRHs in Tanzania. The importance of hospital performance assessment is mentioned and known throughout different studies. ${ }^{[11,13,16]}$ Moreover, the development of hospital performance assessment tools, checking the effectiveness of those tools, has been studied in many papers. ${ }^{[17,18]}$

The improvement of EHPA average scores was probably influenced by the intervention of different project activities. Hence, the authors thought it was important to clarify the following questions to conclude how the contributions of the EHPA improve the performance of the RRHs:

- Is the EHPA tool effective for assessing the performance of RRHs?

- How does the EHPA influence the actual management of hospitals?

- What are the positive factors for conducting hospital performance assessment successfully?

\section{METHODS}

\subsection{Establishment of EHPA team}

EHPA assessors were nominated from MoHCDGEC officials and hospital staff who have been engaged and experienced in hospital planning, financing, commodity management, infection prevention and control, quality management, and so on. Then, they were trained on EHPA tool use, interview methodologies, and data analysis. This training was very important for reducing the variation of assessment results among teams. Then, assessors were divided into three groups and sent to 28 RRHs to conduct the EHPAs. After the assessment, the results were summarily compiled and analyzed for feedback sessions.

\subsection{Performance assessment of RRHs}

Basically, three EHPA teams were formulated based on the areas of expertise and experience. Each team was composed of four to five people with expertise in medicine, nursing, administration, and quality. EHPA teams spent three days (at one RRH) to collect necessary data and information. During the assessment, a quality improvement team (QIT) and/or hospital management team member accompanied the EHPA team to provide logistical support for the smooth operation of the assessment. After information collection, data were compiled and summarily analyzed to develop feedback. At the end of the assessment, a feedback session was organized for RRHMT members to share the findings.

During data collection, the assessors had to observe and follow the instructions given in the tool (checklist) in each assessment area. Some areas/indicators required the use of one, combined, or all of the following methodologies: 1) Document review; 2) Physical check / photo-taking; 3) Observation of practice; 4) Interview of staff; 5) Interview of patients/clients.

\subsection{Compilation and analysis of data and dissemination of EHPA results}

The summaries of results for each RRH were further analyzed by the assessment teams and compiled into an EHPA annual report. Additionally, comparisons of data with the previous year's EHPA were conducted to measure the improvement in performance. This working session for data compilation and analysis was usually conducted between seven to ten days. After completion of data compilation and analysis of the results, the results of EHPA were explained in detail and disseminated to RRHMTs at the Medical Officer In-charge meeting. Figure 3 explains the annual flow of EHPA related activities. 


\begin{tabular}{|c|c|c|c|c|c|c|c|}
\hline \multicolumn{5}{|c|}{ External Performance Assessment Checklist for Regional Referral Hospital } & & \multirow[b]{2}{*}{ Score } & \\
\hline NO. & INDICATOR & QUESTION/VERIFICATIONMETHOD & RESPONSES & $\begin{array}{c}\text { Means of } \\
\text { Verification }\end{array}$ & \begin{tabular}{|c}
$\begin{array}{c}\text { Departments } / \mathrm{Ln} \\
\text { its }\end{array}$ \\
\end{tabular} & & $\begin{array}{l}\text { Remarks } \\
\text { Comments }\end{array}$ \\
\hline \multicolumn{8}{|c|}{ AREA 1: LEGALITY } \\
\hline 1.1 & Valid Licence & $\begin{array}{l}\text { Does the health facility have a valid } \\
\text { license for provision of services? } \\
\text { Check for presence of: } \\
\text {-Registration and up to date license for } \\
\text { Private HFs as per Private Health } \\
\text { Advisory Board Regulations } \\
\text {-OR MSIMBO(HMS) number for } \\
\text { Public Facilities OR HFR } \\
\end{array}$ & $\begin{array}{l}\text { Y. Registration and up to date license } \\
\text { for private facilities from Private } \\
\text { Health AdvisoryBoard OR Msimbo } \\
\text { number for public facilities OR HFR } \\
\text { N. No license OR license not up to } \\
\text { date for Private HFs as per Private } \\
\text { Health AdvisoryBoard OR no } \\
\text { Msimbo number for public facilities } \\
\text { OR HFR }\end{array}$ & & Administration & & \\
\hline 1.2 & Service Agreement & $\begin{array}{l}\text { Does the facility have a service } \\
\text { agreement with the government? } \\
\text { If applicable, ask the facility manager to } \\
\text { show you the service agreement. }\end{array}$ & $\begin{array}{l}\text { Y. Valid service agreement in place } \\
\text { N. No service agreement or not valid } \\
\text { NA. For public facilities }\end{array}$ & & Administration & & \\
\hline \multicolumn{8}{|c|}{ AREA 2: HOSPITALMANAGEMENT } \\
\hline 2.1 & \multicolumn{5}{|l|}{ Facility Management } & & \\
\hline 2.1 .1 & Organization structure & $\begin{array}{l}\text { Is there an organization structures for the } \\
\text { hospital and department that are openly } \\
\text { displayed? } \\
\text { Check Hospital and department } \\
\text { organogram-administration block and in } \\
\text { at least three departments }\end{array}$ & $\begin{array}{l}\text { 3: Observed correct organizational } \\
\text { structures documented and displayed } \\
\text { in administration block and in at } \\
\text { least three departments } \\
\text { 2: Organization structures } \\
\text { documented but outdated or not } \\
\text { displayed } \\
\text { 1. No organization structure } \\
\text { documented }\end{array}$ & & $\begin{array}{l}\text { Administration } \\
\text { OPD } \\
\text { Internal } \\
\text { Medicine W } \\
\text { Pharmacy }\end{array}$ & & \\
\hline 2.12 & $\begin{array}{l}\text { Human Resource } \\
\text { available in the } \\
\text { Hospital }\end{array}$ & $\begin{array}{l}\text { How many staff are available at this } \\
\text { hos pital based on staffing level? } \\
\text { Ask the hospital manager for the number } \\
\text { of staff available compared with } \\
\text { establishment (Annex 1) } \\
\end{array}$ & \begin{tabular}{|l|} 
3: More than $75 \%$ of staff is \\
available \\
$2: 40-75 \%$ of staff is available \\
1: Less than $40 \%$ of staff is available
\end{tabular} & $\begin{array}{l}\text { Annex.1 } \\
\text { (Personnel list) }\end{array}$ & $\begin{array}{l}\text { Administration } \\
\text { (HRH) }\end{array}$ & & \\
\hline
\end{tabular}

Figure 1. Example of EHPA checklist

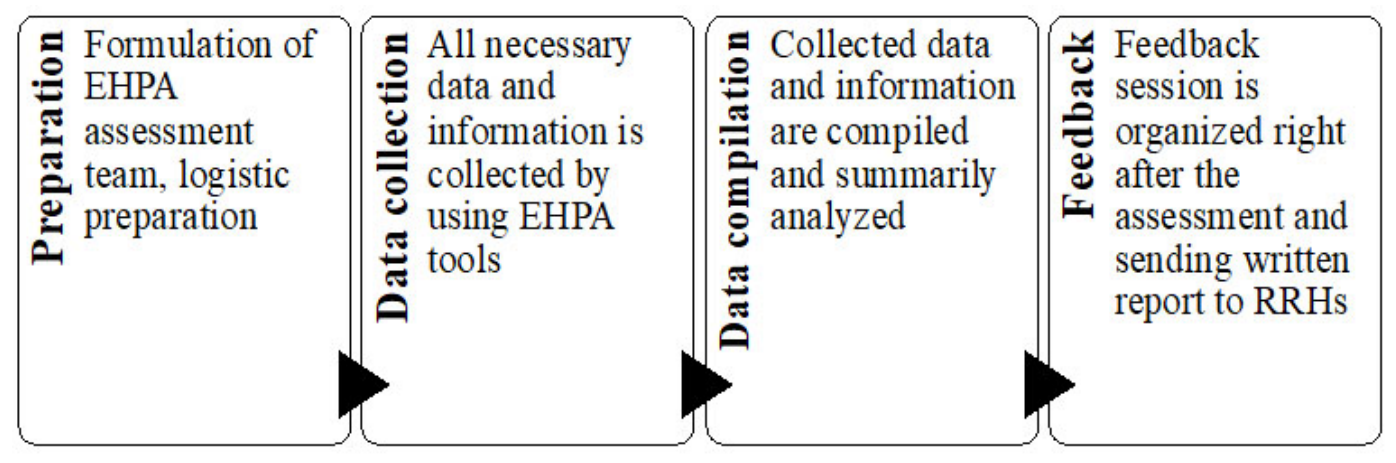

Figure 2. Flow of EHPA at RRHs

\section{Results}

\subsection{Improvement in RRH performance}

Table 3 and Figure 4 show the transition of the EHPA average score from 2017 to 2019. Statistical significance was observed among EHPA average scores $(p<.001)$. The EHPA average score has been improved from 66.3 in 2017 to 77.6 in 2019. As shown in Figure 5, the number of RRHs with an average score above 71 increased from 25\% in 2017 to 57\% in 2018, and further increased to $79 \%$ in 2019 . This indicates that the overall performance of RRHs has improved. 


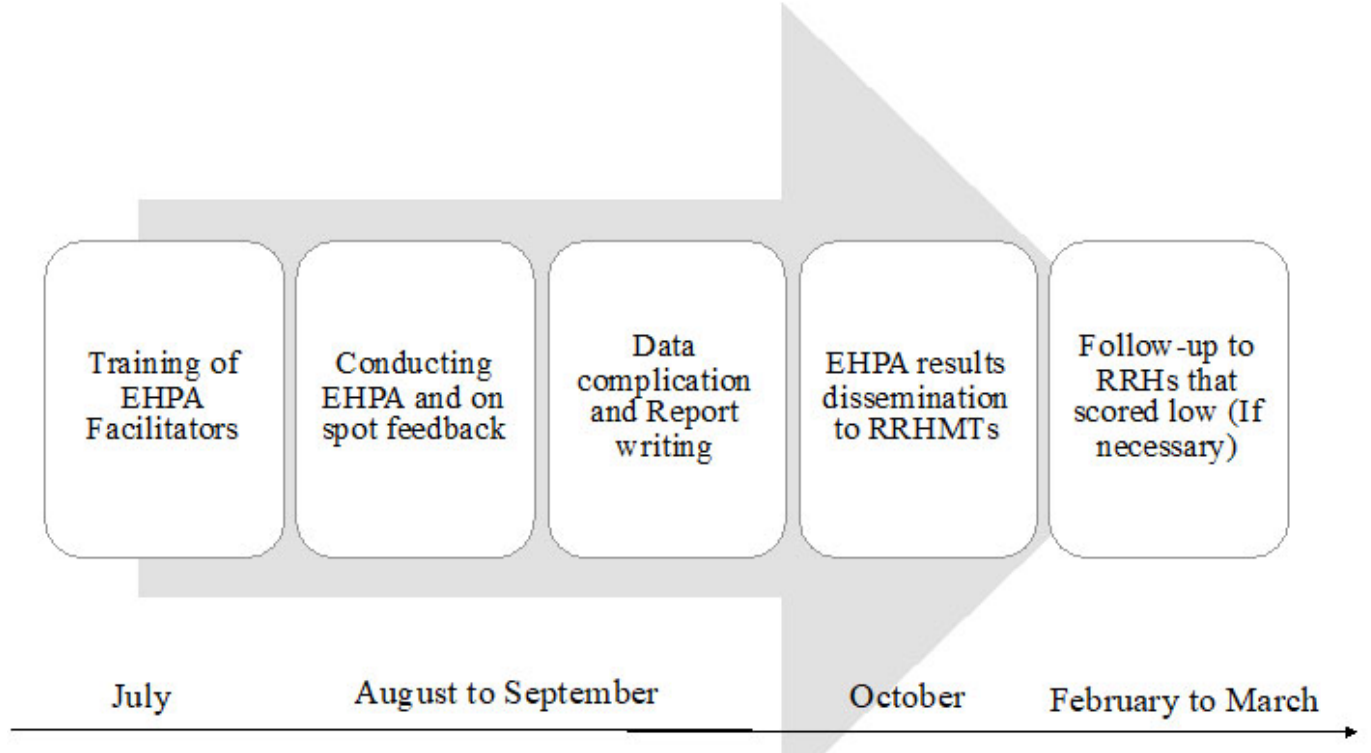

Figure 3. Annual schedule for EHPA related activities

Table 2. List of 14 annexes for the EHPA checklist

\begin{tabular}{llll}
\hline Sq\# & Annexes documents & Sq\# & Annexes documents \\
\hline 1 & Personnel List & 8 & Tracer Medicines \\
2 & Revenue Collection Checklist & 9 & Checklist for Tracer Medicine in selected Dept. \\
3 & Checklist of HMIS registers and related tools & 10 & Emergency Equipment List on OT \\
4 & Emergency medicine checklist / & 11 & Client exit interview \\
5 & Emergency equipment checklist & 12 & SOPs for Dispensing \\
6 & Standard Equipment and Furniture List & 13 & $\begin{array}{l}\text { Protocols for OT (Refer WHO (2007), Best Practice } \\
\text { Protocols Clinical Procedures Safety }\end{array}$ \\
7 & Recommend antiseptic and disinfectant & 14 & Essential Post-mortem/autopsy Equipment \\
\hline
\end{tabular}

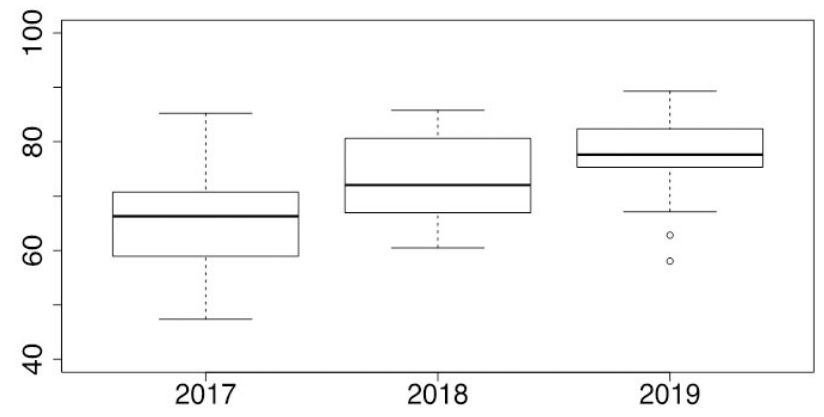

Figure 4. Box plot of EHPA average scores from 2017 to 2019

Positive changes in the performance of RRHs can be seen from the changes in standard deviation $(S D)$ too. As shown 6 in Figure 6, from the change in EHPA average scores and standard deviation, the performance of RRHs has improved year by year and the difference among the RRHs is also shrinking. This indicates that RRH performance has been raised overall.

\subsection{Improvement of RRH performance by area}

As shown in Figure 6, the improvement in performance from 2017 to 2019 by the EHPA area was analyzed. The average scores of each area showed improvement every year, and the performance of RRHs has improved compared with the level in 2017. Area 2 (Hospital management) scored highest among all areas throughout the three years. The score was increased year by year, which indicates that the managerial 
capacity of the RRHMT has been strengthened. Area 3 (Use of hospital data for planning and service improvement) was much improved from 2017 to 2018; however, there was little improvement from 2018 to 2019 . Weak utilization of data and information was also echoed as a challenge in the health facility management during the mid-term review of HSSP IV.

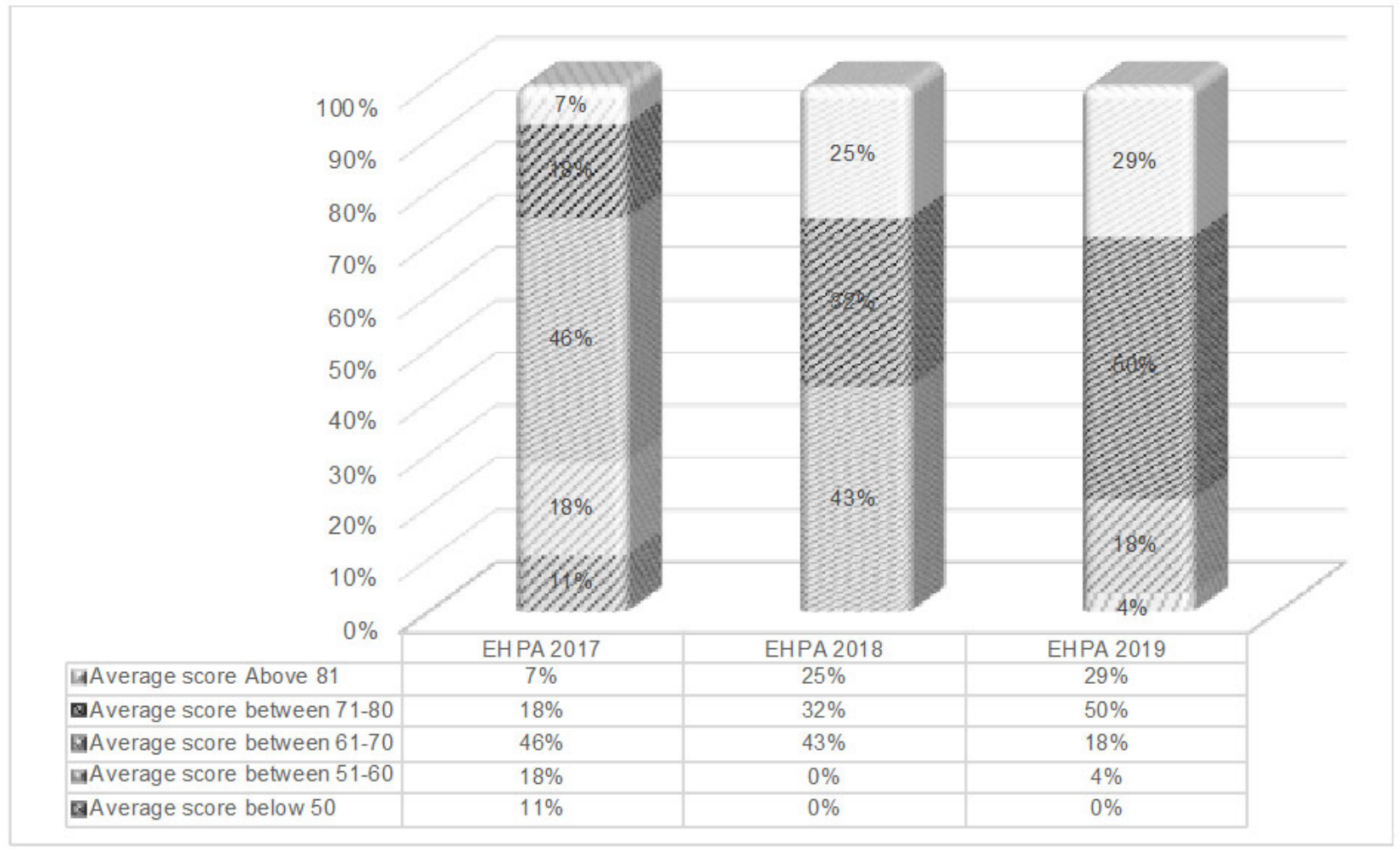

Figure 5. Distribution of EHPA average scores from 2017 to 2019

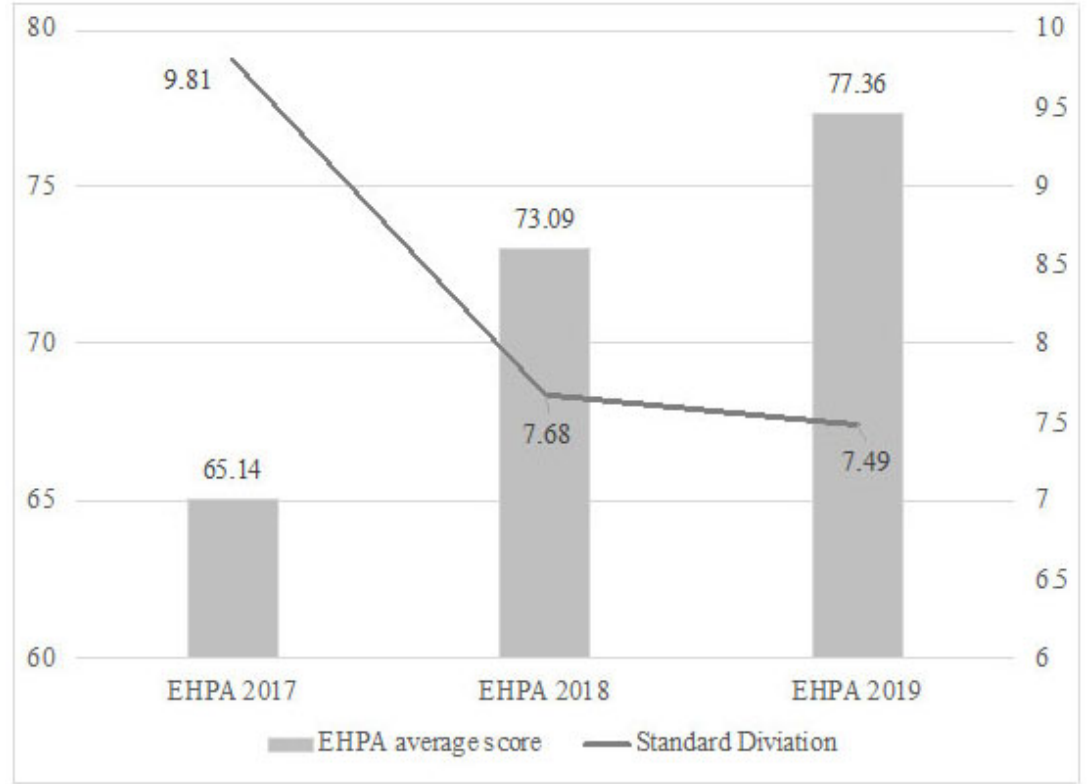

Figure 6. Comparison of EHPA average scores for 2017, 2018, and 2019 
Area 4 (Staff performance assessment), Area 5 (Organization of service), Area 6 (Handling emergencies and referral), and Area 7 (Client focus) made good improvements from 2017 to 2019. This trend indicates that a comprehensive system for providing healthcare services is gradually being established in RRHs. It seems that quality management and health resources management with proper allocation of resources is carried out well by RRHMTs.
On the other hand, there was very little improvement in Area 8 (Social accountability) and Area 9 (Hospital infrastructure) throughout the three years. Area 10 (IPC, safety measures and risk management), Area 11 (Clinical service), and Area 12 (Clinical Support Service) that are related to healthcare service provision by RRHs were indicators that showed little improvement throughout the three years.

Table 3. Transition of EHPA average scores from 2017 to 2019

\begin{tabular}{lllll}
\hline & $\mathbf{2 0 1 7}$ & $\mathbf{2 0 1 8}$ & $\mathbf{2 0 1 9}$ & $p_{\text {-value }}$ \\
\hline Median & 66.3 & 72.0 & 77.6 & $<.001$ \\
(interquartile range: IQR) & $(11.1)$ & $(13.4)$ & $(6.7)$ & \\
\hline
\end{tabular}

Note. "Wilcoxon rank sum test of the scores between 2017 and 2019

Table 4. Summary of responses from RRHMTs on usefulness of EHPA

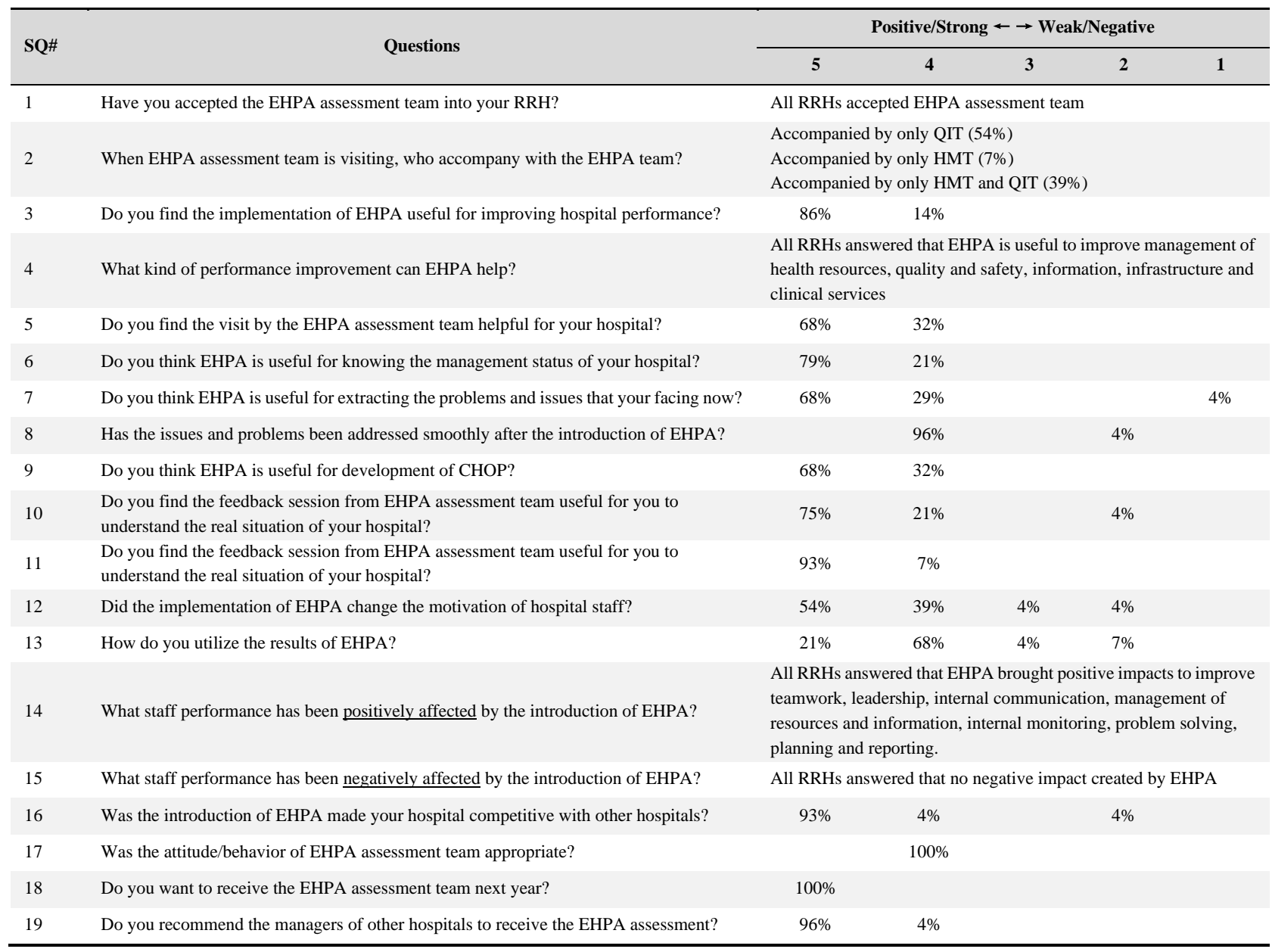

\subsection{Usefulness of EHPA for RRHMTs}

The questionnaire was sent to 28 RRHMTs and all of them responded. Table 4 summarizes the responses on the usefulness of EHPA from 28 RRHMTs. Based on the results of Questions 3 and 4, the EHPA evaluation was effective in improving all aspects of hospital management, including financial management, inventory and commodity management, personnel management, and quality and safety management, 
for all 28 hospitals. Based on the results of Questions 14 and 15, the implementation of the EHPA only had a positive impact that was useful for RRHMTs, and all RRHMTs responded that EHPA had no negative impacts. From the results of Questions 18 and 19, all 28 hospitals were satisfied with the implementation of the EHPA tool and had a positive opinion on conducting similar surveys at other hospitals.

From the results of Question 2, it was determined whether any RRHMT members, other than QIT members who had accompanied the EHPA, had any impact on hospital management duties. Although there was no statistically significant difference, the comprehensive hospital operation plan (CHOP) assessment scores and internal supportive supervision (ISS) scores would likely have been higher if the RRHMT members accompanied the assessors in the EHPAs as shown in Table 5.

Table 5. Differences in EHPA average scores between QIT and RRHMT members

\begin{tabular}{lccc}
\hline & \multicolumn{3}{c}{ CHOP median (IQR) } \\
\cline { 2 - 4 } & $\mathbf{2 0 1 7}$ & $\mathbf{2 0 1 8}$ & $\mathbf{2 0 1 9}$ \\
\hline Accompanied by QIT members only & $85.5(5.3)$ & $67.5(13.0)$ & $72.5(9.8)$ \\
Accompanied by QIT and RRHMT members & $84.0(12.3)$ & $74.5(13.5)$ & $75(7.8)$ \\
\hline & & $\mathbf{2 0 1 7}$ & $\mathbf{2 0 1 8}$ \\
\cline { 2 - 4 } & $69.8(4.7)$ & $73.6(6.9)$ \\
Accompanied by QIT members only & $72.7(4.8)$ & $74.9(6.1)$ \\
\hline
\end{tabular}

\section{DISCUSSION}

Some low- and middle-income countries in Africa, such as Botswana and South Africa, have introduced ready-made hospital performance assessment tools such as the PATH issued by WHO to assess the performance of health facilities. ${ }^{[10,11]}$ In Tanzania, different hospital performance tools were introduced by different donors and development partners and tested to measure the performance of public hospitals and other levels of health facilities. ${ }^{[19-21]}$ However, none of them were adopted as official performance assessment tools for RRHs, except EHPA.

Based on past experiences, the MoHCDGEC did not choose ready-made assessment tools because they needed to be localized, and the cost for localization was high and consumed a lot of time. Additionally, single ready-made tools cannot be applied to all levels and types of hospitals. Healthcare services provided at regional hospitals are different from the district and national hospitals. Thus, in 2017, the MoHCDGEC decided to develop and introduce the EHPA in Tanzania to assess the performance of RRHs.

At the beginning, the MoHCDGEC and the project team expected to get the following tangible effects from the introduction of the EHPA: 1) the MoHCDGEC will become aware of how the RRHs operate and at what levels of performance, and how operations and performance are managed by the RRHMTs; 2) Through clarification of weak areas, RRHMTs will be able to take corrective action for improvement.

Due to the implementation process of the EHPA from 2017 Published by Sciedu Press to 2019 and the analysis of the results, the tangible effects were observed and the objectives of the EHPA were achieved. Additionally, some intangible effects were identified through the implementation of the EHPA. First, there was an "improvement of motivation by competing with other RRHs". RRHMT members expressed their willingness to "improve the performance of their hospital better than others" and started to utilize the EHPA results and findings for betterment, which influenced the improvement of EHPA scores in 2018 and 2019. The second effect was that EHPA "strengthened the communication and teamwork among RRHs members". This is related to the first observation in that the process of utilizing EHPA results for betterment involves brainstorming, discussion, and active exchange of opinions among RRHMT members. It seems that this process influenced the strengthening of communication and teamwork among RRHMT members.

As reported in the findings, looking at the changes in EHPA scores by area can provide insights. Area 2 (Hospital management) was highly improved from 2017 to 2019. On the other hand, Area 10 (IPC, Safety measures and risk management), 11 (Clinical service), and 12 (Clinical support service) that represent the performance of health service provision did not improve much. The reason for this is that the EHPA was developed as part of a technical cooperation project to strengthen hospital management, and the majority of the interventions from the project were related to the managerial capacity development of the RRHMT. At the early stage of the project interventions, administrators of RRHs were 
highly involved and the involvement of clinical staff was delayed. The delay of clinical staff involvement could be one of the reasons for the delay in performance improvement of clinical services. Additionally, a shortage of health resources also seems to affect the improvement of clinical service provision. RRHs are facing difficulties in securing financial resources for the procurement of medical equipment. Moreover, a shortage of human resources and medical specialists is also reported by RRHs. ${ }^{[22]}$

Area 8 (Social accountability) and Area 9 (Hospital infrastructure) also did not show signs of improvement. The issues of social accountability and hospital governance by hospital advisory boards were quite new concepts and took RRHMTs time to functionalize. Issues about infrastructure are related to the high costs of construction and rehabilitation of facilities and the procurement of medical equipment. Therefore, it was thought that capital investment was not easily available due to the financial problems that hospitals face.

Based on the results from the questionnaire, it became clear that most of the RRHMTs were aware of the various effects, benefits, and usefulness of introducing EHPA. Unless the hospital management perceived that the assessment did have benefits for them, the findings of the assessment would not be utilized by the hospital to improve their hospital services. Based on the EHPA process, it was revealed that not only did hospitals believe that the assessment provided beneficial results, but also other useful factors, such as better communication, technical support, etc.

During the study, factors that influencing the EHPA assessment were also identified. The first issue that could impact the effectiveness of the EHPA is the skills and knowledge of the EHPA assessors. An EHPA assessor who does not have working experience in a hospital may have difficulty understanding the indicators of the EHPA, as well as the system requirements of hospital service provision, which may lead to weak technical inputs from the field. Therefore, EHPA assessors need to be experienced working at a hospital and knowledgeable about hospital services to provide appropriate technical support to the RRHMTs.

The second issue is the attitude and behavior of the assessors during the assessment. It was realized that the attitude and behavior of EHPA assessors affect the outputs of the assessment. This lesson was learned from an assessment of the quality of service at RRHs supported by another development partner. Based on the information from RRHMTs, this assessment was conducted by assessors who inspected the hospital in an arrogant and domineering manner. Conducting the assessment in an intimidating manner led to many unnecessary negative results, such as hiding required data and information, ignoring advice, not attending feedback sessions, etc. Therefore, EHPA assessors who are well trained to conduct themselves in a supportive and consultative manner during the assessment will be more effective.

The last issue pertains to the way the hospital management team is supported. We thought that technical inputs during the assessment and feedback sessions following the assessment were important for making positive progress. Groene's study also pointed out the importance of feedback and its timeline[10]. The same findings were observed during the process of EHPA implementation. RRHMTs were eager to listen to the results of the assessment at the feedback sessions and sought advice for improving their weak points.

Based on the three-year implementation of the EHPA and the issues stated above, we believe that it is difficult to conduct an appropriate hospital performance assessment unless the following five factors are assured:

- Good quality of evaluation tools (coverage, easy to use, etc.).

- Assessors that are knowledgeable about hospital services.

- Positive attitude and behavior of the assessors (supportive, conscientious).

- Well-structured assessment methods.

- Timely sharing of the results by the assessment team and utilization of the advice by hospital managers.

\section{Conclusions}

Based on the findings, we can conclude that EHPA is an effective approach and tool for assessing the performance of RRHs in Tanzania. In addition, EHPA is beneficial not only for the MoHCDGEC to gather data, but also to help RRHMTs understand the strong and weak points in their operations to help manage the organization, and when to take corrective action to improve their performance. For the EHPA to be effective, the quality of the assessment needs to be assured. EHPA assessors must be well-trained on how to use the EHPA tools and have a good knowledge of hospital services and good communication skills to work with RRH managers and healthcare professionals. Various factors affect the performance assessment of hospitals in low-income countries and more research is needed to further define the success factors. However, we hope this study has contributed to the understanding of the necessity of hospital performance assessment for strengthening hospital management in lowincome countries.

\section{CONFlicts OF INTEREST Disclosure}

The authors declare they have no conflicts of interest. 


\section{REFERENCES}

[1] World Health Organization. Universal Health Coverage: Lessons to guide country actions on health financing. 2014; 21(2007): 20122013.

[2] Mtei G, Makawia S, Masanja H. Monitoring and Evaluating Progress towards Universal Health Coverage in Tanzania. PLoS Med. 2014; 11(9): 9-10. PMid: 25244395. https://doi.org/10.1371/jour nal.pmed. 1001698

[3] WHO.Universal Health Coverage and Patient Safety \& Quality Understanding the central role of PSQ in UHC. 2014.

[4] OECD. Health at a Glance. OECD Publishing. 2017; 49(6).

[5] Republic of Kenya. National and County Health Budget Analysis FY2018/2019. 2019.

[6] Ministry of Health. Uganda Health Account. 2016.

[7] Ministry of Health and Social Welfare. Health Sector Strategic Plan 2015-2020: Reaching all Households with Quality Health Care. Ministry of Health and Social welfare, Tanzania, Dar es Salaam. 2015.

[8] Ministry of Health and Social Welfare. National Health Accounts Year 2010, with sub-accounts for HIV. Reproductive and Child Health. Malaria. 2012

[9] Veillard J, Champagne F, Klazinga N, et al. A performance assessment framework for hospitals: The WHO regional office for Europe PATH project. Int. J. Qual. Heal. Care. 2005; 17(6): 487-496. PMid: 16155049. https://doi.org/10.1093/intqhc/mzi072

[10] Groene O, Klazinga N, Kazandjian V, et al. The World Health Organization Performance Assessment Tool for quality improvement in hospitals (PATH): An analysis of the pilot implementation in 37 hospitals. Int. J. Qual. Heal. Care. 2008; 20(3): 155-161. PMid: 18378511. https://doi.org/10.1093/intqhc/mzn010

[11] Seitio-Kgokgwe O, Gauld RDC, Hill PC, et al. Assessing performance of botswana's public hospital system: The use of the world health organization health system performance assessment framework. Int. J. Heal. Policy Manag.2014; 3(4): 179-189. PMid: 25279380. https://doi.org/10.15171/ijhpm.2014.85

[12] de A. Ramos MC, da Cruz LP, Kishima VC, et al. Evaluation of hospitals that provide care in the public health system, Brazil. Rev. Saude Publica. 2015; 49. PMid: 26247385. https ://doi .org/10 .1590/S0034-8910.2015049005748
[13] Nwagbara VC, Rasiah R, Aslam M. An approach toward public hospital performance assessment. Med. (United States). 2016; 95(36). PMid: 27603363. https://doi.org/10.1097/MD.000000000 0004688

[14] Kabiri N. Developing a Hospital Managerial Performance Assessment Tool in Iran. 2017; 1(4): 198-204.

[15] Ministry of Health Community Development Gender and Elderly and Children. Guideline for Internal Supportive Supervision (ISS) and External Hospital Performance Assessment (EHPA) for Regional Referral Hospitals. 2018.

[16] O'Brien SM, DeLong ER, Peterson ED. Impact of case volume on hospital performance assessment. Arch. Intern. Med. 2008; 168(12): 1277-1284. PMid: 18574084. https://doi.org/10.1001/arch inte.168.12.1277

[17] Duran A, Chanturidze T, Gheorghe A, et al. Assessment of public hospital governance in romania: Lessons from 10 case studies. Int. J. Heal. Policy Manag. 2019; 8(4): 199-210. PMid: 31050965. https://doi.org/10.15171/ijhpm.2018.120

[18] Hamed R, Mohammad K, Zahra K, et al. Indicators of Hospital Performance Evaluation: A Systematic Review. Int. J. Hosp. Res.2014; 3(4): 199-208.

[19] Mboya D, Mshana C, Kessy F, et al. Embedding systematic quality assessments in supportive supervision at primary healthcare level: Application of an electronic Tool to Improve Quality of Healthcare in Tanzania. BMC Health Serv. Res. 2016; 16(1): 1-15. PMid: 27737679. https : //doi.org/10.1186/s12913-016-1809-4

[20] Yahya T, Mohamed M. Raising a mirror to quality of care in Tanzania: the five-star assessment. Lancet Glob. Heal. 2018; 6(11): e1155e1157. https://doi.org/10.1016/S2214-109X (18) 30348-6

[21] Renggli S, Mayumana I, Mboya D, et al. Towards improved health service quality in Tanzania: appropriateness of an electronic tool to assess quality of primary healthcare. BMC Health Serv. Res. 2019; 19(1): 1-16. PMid: 30670011. https://doi.org/10.1186/s129 13-019-3908-5

[22] Regional Referral Hospital Management Project. Annual Assessment Report External Hospital Performance Assessment for Regional Referral Hospitals. 2019. Available from: https : //www.moh.go.tz/en/reports?download=344:3-annual-a ssessment-report-e-xternal-hospital-performance-a ssessment-for-regional-referral-hospitals-2018 